\title{
Agustinos en el proceso de beatificación del Bto. Alonso de Orozco
}

\author{
I PARTE \\ EL PROCESO DE MADRID
}

El proceso de beatifiación del Bto. Alonso de Orozco se revela como una fuente importante de historia de la provincia agustiniana de Castilla durante el siglo XVI, especialmente de la segunda parte. Queremos pasar revista a dicho proceso para poner al servicio de los estudiosos de la historia de los agustinos españoles datos que no se leen en ninguna otra fuente $o$ bien completan otros ya conocidos. Utilizamos como fuente la transcripción del proceso de beatificación del beato hecha recientemente por el P. Luciano Rubio, que ha tenido la bondad de depositar una copia fotostática de su transcripción en el archivo de la provincia agustiniana de Filipinas en Valladolid. Las páginas que se citan a continuación son de esa transcripción a máquina.

Recogemos en este primer ensayo los datos contenidos en la primera parte del proceso, es decir, los del proceso de Madrid, que es el principal, por haber muerto allí el beato, dejando para otra ocasión los de los procesos rogatoriales instruidos en Salamanca, Valladolid, Talavera, Toledo, Granada y Casarrubios.

\section{La traslación de los restos del beato en $1603^{1}$}

Los agustinos de la provincia de Castilla, que habían enterrado al beato en la angosta capilla del colegio de Doña María de Aragón, donde murió en 1591 , pudieron inaugurar una nueva iglesia más amplia en 1603 . Con ese

1. Copia mecanografiada del proceso, pp. 38-61. 
motivo y dados los milagros que hacía y la veneración que muchos le tenían, quisieron trasladar sus restos a la nueva iglesia. Un mes después del traslado el P. Hernando de Rojas ${ }^{2}$, rector del colegio de la Encarnación -que éste era el nombre oficial del colegio de Doña María Aragón- se presentó en Toledo el 1 de febrero de 1603 y ante el notario Benito Martínez presentó un memorial, por el que pedía que se diera comisión al vicario en Madrid de la diócesis de Toledo para que oyera ante notario a algunos médicos de la corte que habían tenido ocasión de examinar el estado de los restos del beato con ocasión del traslado a que acabamos de referirnos.

Vista esta petición por los miembros del consejo del cardenal de Toledo dieron dicha comisión al vicario de Madrid, D. Gutierre de Cetina ${ }^{3}$, por ministerio del notario Juan Gutiérrez. Este documento lleva la fecha del 15 de marzo de 1603. Las sesiones para oír a los médicos comenzaron en Madrid el 20 de marzo y en ellas fueron oídos sucesivamente el Dr. Nicolás Bocangelino ${ }^{4}$, médico de Cámara de la infanta Doña Margarita, el licenciado Lázaro de Soto ${ }^{5}$, médico de Cámara de la emperatriz María, hermana de Felipe II y viuda del emperador Rodolfo II (el cual dijo haber conocido al beato durante 30 años antes de su muerte), el Dr. Bernardino Suárez, médico de Cámara de la misma emperatriz (que había conocido al betao 26 ó 27 años antes de su muerte), el Dr. Francisco González de Sepúlveda, médico de la Inquisición (que le había conocido 15 años antes de que muriese), el Dr. Orozco, médico de la emperatriz (que le había conocido 4 años antes de morir), el cirujano Antonio Gómez (que le conoció 4 años antes de su muerte), y el Dr. Miguel Hermoso, médico de Madrid (que le había conocido durante 12 años).

2. Profesó como agustino en Salamanca en 1577 , tuvo fama de ser de un varón muy espiritual, por lo que el beato Orozco lo escogió como su confesor y le pidió para el colegio de Doña María de Aragón cuando se fundó. Por haber escrito su "Vida de nuestro Padre" - de la que se hace mención más tarde - ha encontrado un lugar en el repertorio de los agustinos escritores de España y Portugal: Gregorio de SANTIAGo VeLA, Ensayo de una biblioteca ibero-americana de la Orden de San Agustín, vol. VI, Madrid 1922, p. 654.

3. Algunos escritos de este eclesiástico, doctor y vicario de Madrid, en su mayoría aprobaciones para la edición de diversas obras de carácter eclesiástico, las señala José Simón DíAZ, Bibliografía de la literatura hispánica, tom. VIII, Madrid 1970, pp. 485-487.

4. Nicolás de Bocángel, oriundo de Génova, de donde eran sus padres, pero nacido en Madrid, fue "uno de los mejores médicos de su tiempo" y lo fue de Felipe III, de la emperatriz María y de la infanta Margarita. Datos biográficos de él pueden verse en: Josef Antonio ÁlvAREZ Y BAENA, Hijos de Madrid ilustres en santidad, dignidades, armas, ciencias y artes, vol. III, Madrid 1791, pp. 132-133.

5. Este médico fue el padre del P. Juan de Soto, como lo dice expresamente este religioso en su declaración, de la que nos ocuparemos más tarde. 
Todos ellos admitieron que su cuerpo, a la distancia de doce años después de la muerte, estaba incorrupto y que no se explicaba esto dada la humedad del sitio y el hecho de haber estado cerrado a cal y canto durante tanto tiempo. Estas sesiones se fueron sucediendo periódicamente y la última tuvo lugar el 26 de mayo de dicho año 1603. De todo lo cual el vicario de Madrid Dr. Cetina levantó el acta correspondiente con fecha 12 de junio de 1603, firmada por el notario Juan Gutiérrez.

El P. Juan de Corquerat ${ }^{6}$, en nombre del colegio de Doña María de Aragón, pidió un transumpto de este documento, con las formalidades del caso, que le fue dado en 13 hojas y que estaba fechado en Toledo el 18 de julio de 1603.

Este documento contiene ya nu pocos detalles históricos, que ilustran, además de los detalles relativos al traslado y reconocimiento del cuerpo, las biografías de los PP. Hernando de Rojas, confesor del beato Orozco, y P. Juan de Corquerat, este último no mencionado en los repertorios generales de la Orden.

\section{La declaración del P. Juan de Herrera, postulador de la causa?}

Otra aportación del proceso está constituida por las declaraciones autobiográficas del P. Juan de Herrera ${ }^{8}$, nombrado postulador de esta causa tanto por el provincial de Castilla, P. Juan de San Agustín, como por la comunidad del Colegio de Doña María de Aragón.

Fue él quien pidió al juez del proceso que se incluyera en las actas la información que acabamos de examinar, con idea de que sirviera para verificar mejor el artículo n. 53 del interrogatorio, sobre el que habían de ser examinados los testigos.

Presentado por el P. Baltasar de Ajofrín ${ }^{9}$, prior en 1618 del colegio de Doña María de Aragón, para que declarara en el proceso ante los jueces ya

6. Este religioso fue probablemente maestro de novicios en S. Felipe de Madrid entre el 8.XII.1584 y el 9.IV.1586, pues firma profesiones junto al P. Gabriel Pinelo, que era vicarioprior. Cfr. Tomás Gonzalez Cuellas, "Libro I de profesiones del convento de S. Felipe el Real de Madrid", en: Archivo Agustiniano 70 (1986) 47-83; sobre el P. Corquerat véanse las pp. 65-66.

7. Proceso, pp. 62-72.

8. Sobre la profesión de este religioso, natural de Madrid, hecha en el convento de S. Felipe el 6 de junio de 1587, véase: T. GonZÁlez CuEllas, "Libro I de profesiones del conventö de San Felipe el Real de Madrid", en: Archivo Agutiniano 70 (1986) 47-83; la de este religioso en la p. 67. Muchas otras noticias en la vida anónima del beato Orozco, que se publica en el mismo número de dicha revista: pp. 325-402.

9. En calidad de prior de S. Felipe firma actas de profesión entre el 21.IX.1591 (¡el beato Orozco había muerto dos días antes!) y el 11.V.1594 y de nuevo por los años 1606-1607. Cfr. Tomás González Cuellas, "Libro I de profesiones...", en: Archivo Agustiniano 70 
constituidos, el P. Juan de Herrera fue el que abrió la serie de los testigos, ofreciendo una declaración no sujeta al orden de los artículos, que resulta no sólo de gran importancia para la vida del beato sino también de notable interés autobiográfico.

He aquí los datos salientes de su declaración: él era en 1618 conventual de S. Felipe el Real, donde había sido tres veces maestro de novicios y seis años sacristán, además de haber sido prior de los conventos de Fontiveros (Avila) y Casarrubios del Monte (Toledo) "cinco años arreo". El P. Juan de Herrera dice haber conocido al beato desde la edad de cuatro años, pues sus padres eran muy conocidos de él y le enviaban a su celda con limosnas para que las distribuyera a los pobres. En ocasiones diferentes curó a sus padres de sus enfermedades, y en cuanto al padre, el beato consiguió de Dios que viviera tres años y medio más, para que su esposa pudiera criar a los hijos.

El P. Herrera dice haber acompañado al beato -un año antes de tomar el hábito como agustino- en un viaje a Talavera, adonde se dirigía para asisistir a la elección de priora en el monasterio de las agustinas que él había fundado. Siendo novicio, ayudó al beato a trasladar su camastro de una habitación a otra, con ocasión de lo cual pudo comprobar la pobreza en que vivía.

Otro detalle del P. Herrera es la curación hecha por el beato del P. Antonio de Velasco, prior del convento de S. Felipe ${ }^{10}$, y cómo durante una conversación del beato y del P. Herrera con dicho prior se descubrió que el beato ni cenaba ni desayunaba, sino que hacía una sola comida al día.

Innumerables son los detalles de la vida del beato que pudo observar este testigo en su condición de compañero del mismo: por ejemplo, cómo desaparecieron misteriosamente unas tijeras que se cayeron al suelo, cosa que el beato atribuyó al demonio; o bien cómo ocultó unas disciplinas llenas de sangre que el P. Herrera hubiera querido coger para conservarlas como reliquia. Dígase lo mismo de la distribucón a un pobre de la mitad de·la poca

(1986) pp. 71-72 y 81. Algunas apreciaciones sobre el gobierno de este religioso en cuanto vicario provincial con ocasión de las repetidas elecciones del P. Agustín Antolínez y la intervención del nuncio, véanse en: Juan QUIJANO, "Memorias para la historia de la provincia de Castilla", en: Archivo Agustiniano, vol. 56 (1962) y 57 (1963) en diversas entregas. Nosotros citamos el extracto con numeración seguida; para este contexto véanse las pp. 62-63.

10. El P. Herrera cita a este religioso entre los hijos del convento de Salamanca ilustres por nobleza, y dice que profesó allí el 18 de marzo de 1544 y que fue prior de aquel convento y que en 1570 era definidor de la provincia. Cfr. T. de HERRERA, Historia del convento de San Agustín de Salamanca, Madrid 1646, p. 288. El P. Velasco firma profesiones como prior de S. Felipe desde el 8.IX.1586 hasta el 7.VIII.1588. Cfr. T. GonZÁlez CuELlas, "Libro I de profesiones...", en: Archivo Agustiniano 70 (1986) pp. 66-68. 
comida que aceptaba una vez cada 24 horas, entrega a los pobres de los regalos que le daban las personas principales, de cómo dormía solo tres horas, etc. etc.

Interesa no poco el detalle que refiere de cómo fue el P. Francisco Cebera, sub-prior de S. Felipe de Madrid, quien le mandó escribir las mercedes que Dios le había hecho y cómo se hizo constar al principio de sus "Confesiones" que las había escrito por obediencia. Más conocidas son, en cambio, las noticias que ofrece sobre las fundaciones de conventos de monjas, el de Talavera, y los dos de Madrid: el de la Magdalena y el de la Visitación, que se llamó después de Sta. Isabel, del cual tuvo su origen el de la Encarnación.

Interesante es también la alusińn a los libros escritos por el beato, de los cuales dice que le eran conocidos 22 como impresos por el beato, pero que sabía eran muchos más, por lo cual "será -dijo él- muy conveniente a la Iglesia Católica y al Romano Pontífice se busquen todos con mucha diligencia y se manden imprimir", pues el beato lo hizo en virtud de dos apariciones que tuvo de la Virgen.

El P. Herera confiesa saber que el beato había recibido de Dios muchas gracias y que había hecho muchos milagros, de los cuales cuenta en particular uno en el que volvió a dejar como estaban dos vinajeras que por descuido había quebrado un niño que le estaba ayudando a Misa, después de lo cual el beato prosiguió impertubado su celebración. Contado ese mismo día lo que había sucedido por el P. Herrera al P. Gabriel Pinelo -"una de las personas mas graves y más estimadas del rey nuestro señor Felipe II y de toda la Religión"- refiere el P. Herrera que el P. Pinelo le aseguró que casos como ésos se podían escribir muchos del beato Orozco "si hubiera un poco de cuidado".

Como se ve, el P. Herera dejó una declaración preciosa por la cantidad de detalles narrados y por las referencias a agustinos, unos conocidos y otros desconocidos, que ilustraron la provincia de Castilla por aquellos decenios.

\section{El testimonio del P. Pedro de Rivadeneira ${ }^{11}$.}

Este religioso fue elegido en 1621 provincial de la provincia de Castilla y en 1630, siendo prior de S. Felipe, fue elegido asistente general de la Orden en Roma, cargo para el cual fue reelegido en 1636 y murió en S. Felipe de Madrid en 1643, habiendo gozado de bastante prestigio ante la corte de

11. Proceso, pp. 106-110. 
España ${ }^{12}$. En el momento de hacer su declaración ante el juez ${ }^{13}$ del proceso (1619) tenía sólo 42 años y declara no haber conocido ni al beato Orozco ni a sus padres. De todos modos fue presentado como testigo pues tenía algo que declarar acerca de algunos artículos del interrogatorio.

Al octavo, por ejemplo, que trataba de la estima que tuvieron del beato las personas reales y altos dignatarios de la corte, narró cómo Felipe II tenía como hoja de señal en un breviario, por el que rezaba, un billete con autógrafo del beato Orozco, y que cuando el beato iba a palacio, el rey mandaba que fuera a bendecir a los príncipes, por la gran estima que tenía de él como de persona santa. La sustancia de esta declaracióon la veremos expuesta con mayor detalle por religiosos que fueron testigos de escenas como las que indicaba el P. Rivadeneira. Nada especial añade a otras preguntas, como aquellas en las que se trataba de la aspereza de su celda y parquedad en los alimentos, o su caridad con los pobres, pero sí añade haber visto y leído muchos de sus libros, "de los cuales se colige el grande espíritu y doctrina sólida y grave con que los escribió...".

A propósito de sus milagros sabía cómo había hecho muchos, especialmente en ocasión de partos, a propósito de lo cual refiere uno que le había referido un tal Felipe Sierra, conocido suyo, ocurrido a una hermana de dicho Felipe. Alude también a la sepultura del beato, enterrado primero bajo el altar mayor de la iglesia antigua del colegio con permiso del Card. Quiroga, arzobispo de Toledo, que tenía un alto concepto de la santidad del beato. El Card. Quiroga, que dio el permiso para la primera sepultura, no pudo darlo en 1603 para el traslado a la nueva iglesia del colegio, pues murió en 1594.

\section{Dos "servidores" del beato Orozco: los PP. Francisco Maldonado y Pedro de la Torre}

Más interesante que la anterior es la declaración del P. Francisco Maldonado ${ }^{14}$, que llegaría a ser entre 1626 y 1632, en que murió, obispo titular de Siria y auxiliar del Card. Infante, arzobispo de Toledo.

12. Estos datos pueden leerse en: T. de Herrera, Historia del convento de San Agustín de Salamanca, p. 200 y 419. Sobre el P. Rivadeneira véase también: Gregorio de SANTIAGo VELA, Ensayo de una biblioteca ibero-americana de la Orden de San Agustín, vol. VI, Madrid 1922, pp. 568-569.

13. Aunque el cabildo de Toledo en sede vacante nombró a dos jueces que se ocuparan del proceso, en realidad estuvo todo él a cargo del juez nombrado por el nuncio Francesco Cennini a petición de los agustinos, como se explica al principio del proceso mismo.

14. Proceso, pp.187-197. Cfr. T. de Herrera, Historia..., p. 297. 
Por las fechas de su declaración (1619), dice ser de 54 años de edad y maestro en S. Teología. Conoció al beato Orozco a partir de 1580 , pues se aconsejó con él para tomar el hábito de agustino y, una vez ya profeso, fue su "servidor" (es decir, el encargado de prestarle algunos pequeños servicios de la vida diaria) por encargo del prior de S. Felipe. En calidad de tal tuvo ocasión de ser testigo de numerosos detalles, de los cuales habla en su declaración. Acerca del artículo octavo confirma la estima en que le tenían las personas reales, cómo leía los evangelios a las mismas en ocasión de achaques, bendecía a los príncipes y les daba a besar la mano. Habiendo parecido mal esto último a algunos y habiéndoselo hecho notar, respondió que les venía bien a los príncipes "para que gozasen de los perdones".

Confirmó el artículo noveno, en que se trataba de cómo pidió permiso a Felipe II para retirarse al convento del Risco, deseoso de abandonar la corte, cosa que el rey le negó decididamente. El P. Maldonado precisa que, como una de las razones aducidas por el beato era la de que estaba endeudado, el rey mandó averiguar cuánto debía y se supo que no debía más de 200 o 300 reales, cosa que cayó en gracia al monarca. Más adelante veremos narrar este mismo episodio a quien fue testigo de la escena.

Numerosos son los detalles que aduce en prueba de su austeridad en la celda -que el beato no le permitió barrer nunca- y austeridad en las comidas y en el sueño. En torno a lo cual refiere cómo sabía que el beato se acostaba "metido en un saco o costal desde los pies hasta debajo de los brazos, para no dar lug r a que entre sus sueños pudiesen llegar las manos a partes vergonzantes", etc.

Después de confirmar la fama de hombre de oración que siempre tuvo y cómo era especialmente aficionado a la calenda y lectura en público de la vida de los santos, ofrece otros detalles acerca de cómo era fama que le había hablado un crucifijo que estaba en el coro de S. Felipe, cómo practicó a veces una mansedumbre heroica con una persona que le ofendió con una bofetada y cómo hizo lo mismo con quienes tuvieron intentos de calumniarle; alude también brevemente a la fama que corría de su perpetua virginidad. El mismo había oído personalmente de boca del beato cómo hasta sus ochenta años lo había sido, confiando en la bondad de Dios en que así sería en el futuro; esto lo oyó el P. Maldonado poco antes de dejarle para ir a hacer sus estudios.

Curiosos los detalles que ofrece sobre las relaciones del beato con el falso profeta Pietro Pirola, cuyos embustes conoció por inspiración divina y proclamó siempre el beato, a quien como retorsión trató de calumniar el falso profeta, anunciando que había de tener un mal fin. Llegada la cosa a 
conocimiento del beato, en nada se inmutó, y ni siquiera quiso hablar mal de quien hablaba tan poco bien de él.

También fue "servidor" de nuestro beato el P. Pedro de la Torre ${ }^{15}$, a quien el proceso presenta como "predicador mayor perpetuo del convento de San Agustín de la ciudad de Burgos y prior que ha sido del convento de San Agustín de Mansilla y procurador general de la religión de la Orden del Señor San Agustín y prior del convento de San Agustín de Burgos, residente al presente en esta corte en S. Felipe".

Dice haber conocido al beato desde el 18 de diciembre -fiesta de la expectación- de 1584 - en que el provincial de entonces, P. Juan de Guevara, le mandó a dicho convento "en el ínterim que se ponía algún curso de artes para estudiar", hasta "la víspera de la festividad del Santísimo Sacramento, que fue a estudiar", es decir le conoció por espacio de unos seis meses. Por su parte dice ser de 50 años de edad.

Confiesa haberle acompañado a visitas fuera de casa, la mayor parte de ellas a predicar en diversos conventos, entre ellos el de la Magdalena "y el noviciado que estaba conjunto a él". Pone de relieve su modestia, la veneración de la gente hacia él, las reprensiones a los que oía jurar, sus visitas a los enfermos, etc. Repite los detalles acerca de su frugalidad, austeridad de su celda, reparto de su comida con los pobres, respeto que le tenía el rey Felipe II y los demás de la corte, etc. etc. Como cosa original narra el caso de un niño o niña sobre quien pasó encima un carro cargado y a quien el beato curó milagrosamente.

\section{Testimonio de los PP. Alonso Verdugo y Juan de S. Agustín}

Inmediatamente después del P. Pedro de la Torre fueron oídos estos dos religiosos, de los cuales el segundo era el provincial en cuyo tiempo se hizo el proceso.

El P. Verdugo ${ }^{16}$ dijo ser entonces de 60 años de edad y el notario le define como "predicador y conventual del convento de S. Felipe de esta villa de Madrid". Se trata de una declaración bastante genérica, donde hay pocas novedades. Una de ellas es decir que en toda la corte se le llamaba "el santo de S. Felipe”, su disposición a tañer el órgano en las Misas aún cuando había en el coro otros que hubieran debido hacerlo -detalle que repiten muchos

15. Ibid., pp. 197-201. De un religioso de este mismo nombre pero sin duda diverso de él refiere Herrera que murió en Salamanca en 1597 después de haber sido muchos años portera de aquella casa y que, abierto su sepulcro en 1612 para colocar en él a otro religioso, hallaron su cuerpo intacto. Cfr. T. de HerRera, Historia..., p. 200.

16. Proceso, pp. 201-206. 
otros testigos- y cómo el célebre agustino P. Maestro Francisco de Castroverde ${ }^{17}$, predicador de Felipe II, no obstante que tenía tanta fama, siempre que tenía ocasión de oír al P. Orozco lo hacía "y decía que salía de sus sermones muy edificado y enseñado". Después de aludir al tratado sobre el "Cantar de los Cantares" escrito por el beato, narra el caso de un parto ocurrido felizmente gracias a la correa del beato, que este testigo mandó traer del colegio. No faltan en su declaración el recuerdo del falso profeta Pirola y el ningún crédito que el beato dio a la llamada "monja de Portugal" ${ }^{18}$, de la que dijo que "era el caso encomendarla a Dios , que era mujer". No falta tampoco la alusión a los monasterios fundados por el beato tanto en Talavera como en Madrid, pero sin detalles especiales.

El testimonio del provincial P. Juan de S. Agustín ${ }^{19}$, de quien se dice aquí que era calificador del Consejo de la Inquisición y que era de 46 años, es sumamente breve y se limita a decir que no conoció ni a los padres del beato ni a él mismo, pero que había oído decir muchas cosas de su santidad. Da la impresión de que fue invitado a declarar por mera cortesía y para que abonara con su participación en las declaraciones el interés que tenía toda la provincia en la feliz conclusión de este proceso para la exaltación de uno de los hijos más esclarecidos de la misma.

\section{El obispo de Plasencia, Fr. Enrique Enriquez, $O S A^{20}$}

A razones de prestigio -aparte interés personal del testigo- se debió sin duda el haber sido llamado a declarar al obispo de Plasencia, Fr. Enrique Enríquez, provincial que había sido de la provincia de Castilla antes de su

17. Algunas indicaciones sobre este célebre predicador pueden verse en: Gregorio de SANTIAGo VelA, Ensayo, vol. I, Madrid 1913, pp. 680-681.

18. La "monja de Portugal" o "monja de Lisboa" era Sor María de la Visitación, a quien defendió y cuya vida escribió Fr. Luis de Granada. El argumento de su "sebastianismo" lo explica Alvaro Huerga en el "Estudio preliminar" a la biografía de esta monja: FR. LUIS DE GRANADA, Vida de Sor María de la Visitación, Barcelona 1962, pp. 1-112.

19. Proceso, pp. 206-207. Para una biografía completa aunque breve de este ilustre agustino que, además de profesor en Salamanca, fue después gran consejero y acompañante del Card. Fernando de Austria, administrador perpetuo del arzobispado de Toledo, muriendo en el colegio de Doña María de Aragón en 1646, véase: T. de HerRera, Historia, p. 398. Más amplia la nota bio-bibliográfica que ofrece G. de SANTIAGo Vela, Ensayo, vol. VII, El Escorial 1925, pp. 118-124. Ofrece un cuadro negativo - le trata de "político" y manejador, aparte otros defectos Juan QuiJANo, Memorias, pp. 218-220.

20. Proceso, pp. 230-233. También sobre este ilustre hijo de la provincia de Castilla, de noble linaje (marqueses de Alcañices y de Aguilar), obispo de Osma, electo de Cuenca y arzobispo de Granada, y obispo de Badajoz, ofrece los datos fundamentales T. de HERRERA, Historia, pp. 179, 181, 287 y 405. Véase también: G. de SANTiAgo Vela, Ensayo, vol. II, Madrid 1915, pp. 320-322. Expresa un juicio positivo sobre su gobierno el P. Juan QuIJANO, Memorias, pp. 5758 del extracto. 
elevación al episcopado. Este prelado agustino comenzó por decir que tenía 64 años de edad y que no había convivido nunca en un mismo convento con el beato. De todos modos le conocía porque, en sus viajes de Alcalá -donde él era Rector de aquel colegio- a Madrid se hospedaba en S. Felipe y tuvo ocasión de verle.

Por todo esto sabía que el beato era muy limosnero y que estaba siempre ocupado con sus "pobrecitos" -así les llamaba- para los cuales le pidió alguna vez limosna estando en Alcalá y él se la mandó. Dice dudar de que hubiera persona más santa en su tiempo y a esta santidad se debía el aprecio que de él tenían en la corte, etc. Tenía noticia también de las manifestaciones de veneración hacia él que tuvieron lugar en Madrid con ocasión de su muerte y cómo la gente quería a toda costa hacerse con trozos de su hábito.

\section{Tres agustinos en abono del hermano Francisco de Mondéjar ${ }^{21}$ y otros tres en abono del P. Luis de Valdivieso.}

Habiendo sido escuchado como testigo en el proceso un señor llamado Juan de Hita, de 60 años de edad y vecino de Madrid, el cual narró cosas muy curiosas acerca de las mortificaciones del beato y sobre otros detalles por haber sido testigo de ellas con ocasión de haber sido invitado a observar de escondido al beato por un tío suyo fraile, llamado Fr. Francisco de Mondéjar, ya difunto, el comisario del proceso, Licenciado Gonzalo de los Ríos, ordenó al notario con auto firmado el 6 de junio de 1619, que hiciera averiguaciones sobre la credibilidad y cualidades morales de dicho hermano lego.

Para ello fueron presentados como testigos en abono del hermano los PP. Juan Becerra ${ }^{22}$, Alejo de Olmos ${ }^{23}$ y Alonso de Soto ${ }^{24}$, los tres agustinos. De los dos primeros se dice que eran "predicador y conventual" de S. Felipe, y al tercero se le llama sólo conventual. Todos ellos dicen haber conocido durante varios años al hermano y dan testimonio no sólo de que fue durante un largo período compañero del beato, sino también hombre de vida inculpable. Este testimonio daba mayor fuerza a las declaraciones de Juan de

21. Probablemente se alude aquí al hermano "Francisco, portero", de quien escribe Herrera brevemente que fue portero de $\mathrm{S}$. Felipe y que murió por los años 1611 , "tenido por sus virtudes en gran veneración": T. de HerRera, Historia, p. 296. Es sin duda el mismo del que hace un singular elogio el P. Juan Quijano en sus Memorias, p. 110 del extracto.

22. Proceso, pp. 334-335.

23. Proceso, pp. 335-336. También este religioso profesó en S. Felipe de Madrid el 24 de agosto de 1596. Cfr. Archivo Agustiniano 70 (1986) 74.

24. Proceso, pp. 336-337. Un Fr. Alonso de Soto, originario de Chinchón, profesa en S. Felipe de Madrid el 1 de mayo de 1573. Cfr. Archivo Agustiniano 70 (1986) 56. 
Hita, pero nada dijeron en esta ocasión los declarantes acerca del beato, porque dos ellos (los PP. Becerra y Soto) serían llamados más tarde a declarar sobre los artículos del interrogatorio.

Caso parecido sucedió con la declaración de la monja Sor Francisca de los Angeles, religiosa del convento de la Concepción Jerónima de Madrid, la cual, habiendo dicho que había oido contar en su convento a la M. Concepción Jerónima cómo el agustino P. Luis de Valdivieso ${ }^{25}$ había dicho que el beato Orozco había visto, durante la celebración de una Misa en domingo, subir al cielo el alma de su sobrina Sor Catalina de Nazaret, religiosa en dicho convento, el juez del proceso ordenó nuevamente al notario Juan de Alegría, con auto firmado en Madrid el 17 de junio de 1619, que averiguase las cualidades morales del P. Luis de Valdivieso con el fin de compulsar la credibilidad de las declaraciones de la M. Francisca de los Angeles. Así se hizo y para ello fueron presentados los agustinos PP. Luis de los Ríos, Bartolomé Arias ${ }^{26}$ y Nicolás Botello.

El primero de estos religiosos, que era maestro en teología y definidor mayor de la provincia de Castilla, sería llamado más tarde a prestar declaración sobre el beato y dio un testimonio de casi 40 folios, uno de los más completos y bellos de todo el proceso. En esta ocasión se limitó a abonar al P. Valdivieso, al cual dice haber conocido por espacio de más de 16 años, del cual dice que era predicador y que fue un "varón justo y fraile de mucha verdad y muy anciano".

"Cosa parecida dijeron los otros dos, los PP. Bartolomé Arias y Nicolás Botello, de los cuales se escribe que eran predicadores y conventuales de $\mathrm{S}$. Felipe de Madrid. El primero dice haber conocido más de seis años al P. Valdivieso, que era "predicador de la Orden de San Agustín y rector del colegio de Alcalá"; y el segundo dice haberle conocido por espacio de cuatro años, tanto en Madrid como en Salamanca, abonando ambos sus cualidades religiosas y morales.

\section{El testimonio del P. Sebastián de Avellaneda ${ }^{27}$}

El 18 de junio de 1619 fue llamado a declarar el P. Sebastián de Avellaneda, un religioso de 52 años, predicador y conventual de S. Felipe en

25. Este religioso parece que fue maestro de novicios en el convento de Toledo en 1557, a juzgar por las tres profesiones que firma en dicho año, junto con el prior de la casa. Cfr. Ignacio Aramburu, "Las profesiones deligiosas del convento de Toledo. Libro I (1595-1566)", en: Archivo Agustiniano 67 (1983) 355-381; sobre el P. Valdivieso en la p. 377.

26. El P. Bartolomé Arias profesó en S. Felipe de Madrid el 21 de octibre de 1588. Cfr. Archivo Agustiniano 70 (1986) p. 68.

27. Proceso, pp. 420-428. 
Madrid, el cual dice que conoció al beato Orozco por espacio de año y medio antes de su muerte, tiempo durante el cual le acompañó en muchos menesteres.

Declara sobre la veneración de la gente, que a veces "muchos señores de títulos y otras personas que iban en coches o caballos, viendo al dicho santo, todos se salían de los coches y se apeaban de los caballos y delante del dicho santo Orozco se arrodillaban y le pedían la mano para la besar y que les echase su bendición". Confirma los conceptos que ya sabemos acerca de su vida penitente, asistencia a los pobres, pero señala también cómo no podía caminar bien por tener callos en los pies, y cómo su confesor, el P. Damián de la Serna ${ }^{28}$, daba testimonio de su inocencia de vida, y cómo el beato no quería que se le llamase Maestro, diciendo que no lo era. Otros detalles se refieren a su cuidado a los enfermos en los hospitales, o a su celo en la predicación en hospitales y conventos de monjas, tareas en las que el P. Avellaneda le acompañaba.

Seguidamente cuenta la curación de un alcalde de corte llamado Claudio de Cos y con mayor detalle la de D. Hernando de Vega ${ }^{29}$, presidente del Consejo de Indias y la Misa de inauguración del monasterio de la Encarnación en la calle del príncipe, ceremonia en la que él ayudó al beato.

\section{El testigo más importante: $P$. Luis de los Ríos ${ }^{30}$}

No es fácil encontrar datos sobre este religioso en los repertorios agustinianos ${ }^{31}$, pero jugó un papel importantísimo en la provincia de Castilla durante los últimos decenios del siglo XVI y primeros del XVII. Fue oído por el juez de esta causa el 18 de julio de 1619 y se le presenta como "definidor mayor" de la provincia. Este testigo dijo haber conocido al beato desde hacía 44 años en que tomó el hábito en $S$. Felipe ${ }^{32}$, y que tenía 60 años de edad por la época del proceso.

28. El P. Damián de la Serna aparece como testigo en la registración de la profesión de Fr. Juan Montalvo, el 4 de junio de 1583, el cual había profesado el 9 de marzo de 1580 y no se había escrito en el libro de profesiones. Cfr. Archivo Agustiniano 70 (1986) p. 62.

29. Fernando o Hernando de Vega y Fonseca, de quien se habla después con nuevos detalles, fue preconizado obispo de Córdoba el 20 de marzo de 1591 y murió el 3 de septiembre del mismo año, 16 días antes que el beato Orozco. Véase G. van GuliK - C. EUBEL, OFMConv, Hierarchia catholica, vol. III, Münster 1923, p. 178.

30. Proceso, pp. 429-470.

31. Nosotros hemos ofrecido no pocos de verdadero interés en dos estudios publicados respectivamente en: Augustinianum 9 (1969) 5-29 y Archivo Agustiniano 61 (1977) 159-215.

32. No obstante lo que él afirma, no hemos visto su nombre en la lista de profesiones de $\mathrm{S}$. Felipe, citada numerosas veces en este artículo y editada en: Archivo Agustiniano 70 (1986) 47-83. 
Dice estar informado de la nobleza de los padres del beato por un deudo suyo que era del Consejo de Castilla y se confesaba con el beato.Del bautismo del beato y de su devoción a la Virgen por habérsele aparecido a su madre antes de que él naciera dice estar informado por su maestro de novicios, el cual lo había sabido a su vez del propio maestro, que había sido el P. Diego López ${ }^{33}$, uno de los Padres más autorizados de la provincia. A la misma fuente se remontaban sus conocimientos de la vida piadosa del beato durante su adolescencia, con su servicio en la iglesia de Talavera y en la catedral de Toledo.

Sobre su rofesión en el convento de Salamanca en manos de S. Tomás de Villanueva estaba informado porque "estando allí estudiando (el P. de los Ríos), lo vio en el libro antiguo escrito". Que el beato se había mantenido así toda la vida desde su mocedad, no cediendo en su observancia cuando fue prior en algunos conventos, lo sabía por los "religiosos y prelados antiguos de esta provincia que alcanzaron el tiempo de la mocedad del santo Orozco".

El artículo octavo trataba de la veneración que reservaban los nobles de la corte y los reyes de España al beato. El P. Luis de los Ríos dice saber muchas cosas por haberle acompañado, después que fue profeso, por espacio de dos años. A su piedad se debía que Felipe II le hubiera hecho su predicador, para tenerle siempre en la corte, como se lo oyó decir él muchas veces a D. Jerónimo Manrique ${ }^{34}$, capellán mayor de S. Majestad. Y así, "todas las veces que S. M. estaba enfermo y fatigado de la gota le mandaba a llamar para que le dijese los evangelios y le pusiese las manos encima y le mandaba que le encomendase a Dios y dijese Misa por él”. Lo mismo hacía cuando enfermaban los príncipes. A este propósito narra un hermoso episodio relacionado con una enfermedad del príncipe -futuro Felipe III- en el que el P. de los Ríos estuvo presente y vio toda la escena. Bellísimo también el otro lance con la reina Ana cuando dio a luz al príncipe -futuro Felipe II- en que no quiso devolver al beato su correa hasta que no se sintió del todo buena. Episodio narrado con tal lujo de detalles, que parece como si estuviera uno

33. Acerca de este religioso, que profesó en 1506, que vivía todavía, muy venerado por sus virtudes, en 1569 y del cual no se dice el año de su muerte, se leen algunas noticias interesantes en: T. de Herrera, Historia, p. 235.

34. D. Jerónimo Manrique de Lara era licenciado en derecho y fue presentado por Felipe II para dos obispados: fue nombrado obispo de Cartagena el 19 de enero de 1583 y trasladado al de Avila el 5 de abril de de 1591. Murió el 1 de septiembre de 1595. Cfr. G. van Gulik - C. EuBEL. OFMConv, Hierarchia catholica, vol. III, Münster 1925, pp. 154 y 92 respectivamente. Este epsodio de la vida del beato Orozco debe ser anterior al nombramiento episcopal y por tanto anterior al 1583 . 
asistiendo a los divesos lances del mismo, que terminó la recuperada salud de la reina.

Relacionado con la veneración de Felipe II al beato está también otro episodio, que el P. de los Ríos vivió en persona, pues, yendo en cierta ocasión al Escorial, donde se había corrido la noticia de la muerte del beato Orozco, el P. de los Ríos les desengañó, causando gran contento al monarca y a toda la corte. Este episodio lo narra también otro testigo (el P. Chaves), pero el P. de los Ríos dice haber presenciado, durante este viaje al Escorial, cómo Felipe II cortaba con las tijeras en cinco partes un billete de Doña María de Aragón al beato y la respuesta de éste, quedándose con aquélla en la que estaba la firma, que puso en su breviario, dando las demás a sus hijos y a Doña María de Aragón. El mismo P. de los Ríos pudo comprobar más tarde, con ocasión de otra visita al Escorial, cómo Felipe II tenía todavía en su breviario, como señal, el autógrafo del beato Orozco.

El mismo testigo acompañó varias veces a palacio al beato y en dos ocasiones en patricular le vio hablando al rey e insistiendo para que le dejara retirarse al convento del Risco; cosa que él le negó repetidamente. Unido a este episodio está la oferta de dinero al beato por parte del rey para "pagar sus deudas", es decir, para satisfacer el deseo que tenía de "sacar unos pobrecicos que estaban en la cárcel porque los hallaron cazando". La cosa terminó en que poco después venía D. Jerónimo Manrique con dos lacayos "que cada uno traía un talegón grande lleno de monedas de plata" de parte de S. Majestad.

Respondiendo a la pregunta n. 10 del interrogatorio, el P. Luis de los Ríos asegura haber entrado en los agustinos edificado de ver al beato en casa de un deudo suyo con "gran compostura, mortificación y modestia". De sus ásperas penitencias en el convento fue ya testigo de vista por espacio de más de dos años. Y por haber entrado una vez en su celda, hurtándole el cuerpo, y ser sorprendido curioseando en ella, le costó al P. de los Ríos el castigo de cuatro disciplinas que le impuso su maestro, "que no se pudo acabar con él dicho P. Orozco que le perdonaran una".

Infinitos son los detalles que ofrece sobre su vida diaria, asistencia al coro, devociones, etc., con ocasión de lo cual narra el milagro que el beato hizo al hallarse intacta una lámpara de aceite que el P. de los Ríos había dejado caer hasta el suelo de la iglesia desde el coro alto. El haber narrado este prodigio en la comunidad le costó otras dos disciplinas...

En el contexto de su caridad con los pobres recuerda aquel episodio en que el beato fue a Felipe II a pedirle algún dinero para pagar sus deudas, el cual, después de apretarle mucho, le hizo confesar que eran 100 ducados. "El rey, con ser tan grave y modesto, no pudo detener la risa y dijo :"ibien empe- 
ñado me dejaréis!", y mandó que se lo dijera a D. Jerónimo Manrique; el cual, después de reprocharle que no se lo hubiera pedido a él, proveyó para que pudiera dar a los pobres. El beato al reproche del limosnero replicó que a él le tenía reservado "para otro aprieto".

Los episodios se suceden sin parar en esta larga declaración, donde parece que el juez dejó hablar libremente a este religioso que tenía tanto que contar acerca del beato y que dijo alguna cosa original a casi todas las preguntas.

No pudiendo absolutamente reseñar aquí todas las noticias de este testigo, cerramos la relación con un dato que no sería justo dejar en el olvido. Narra el P. de los Ríos que estando él en Roma tratando de la beatificación

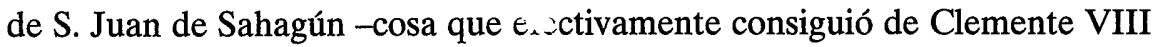
en $1601^{35}$ - al besarle el pie por la merced hecha a la Orden, el papa le preguntó por cuánto tiempo le iba a dejar en paz, pues le tenía cansado con sus importunidades. El P. de los Ríos le dijo que el tiempo que necesitara para ir a España a llevar a la provincia la buena noticia de la beatificación y volver a Roma, pues le escribían que se había encontrado incorrupto el cuerpo del P. Orozco con ocasión de su traslado de la iglesia vieja a la nueva. Respondió el papa: "Yo le conocí y le tuve por tal (santo varón), y me huelgo mucho y os oiré de buena gana". Pero el negocio de la beatificación de este santo fraile, no obstante la favorable disposición de un papa que le había conocido durante un viaje a España y que además había sido Cardenal Protector de la Orden, iba a requerir no sólo años, sino también siglos, pues desde que ocurrió este episodio hasta la beatificación en 1881 habían de pasar más de dos y medio.

\section{Un agustino recoleto en el proceso del beato Orozco}

En 1619 tenía 62 años el P. Gregorio de Alarcón ${ }^{36}$, que en su juventud y antes del comienzo de la recolección había sido estudiante agustino en el

35. En 1603 el mismo papa Clemente VIII concedió a toda la Orden la extensión del rezo del beato, y el 24 de noviembre del mismo año se la concedió a los pueblos de Sahagún y Cea. Cfr. T. de Herrera, Historia, p.72, al final de la biografía de S. Juan de Sahagún, que ocupa las páginas 57-78, donde se da en castellano el breve papal de la beatificación, pp. 72-73.

Parece claro que la entrevista del P. Luis de los Ríos con el papa tuvo lugar en 1603, después de la concesión del oficio, cuando habían llegado ya a Roma las noticias de la traslación del cuerpo del beato.

36. Proceso, pp. 638-643. Profesó en Salamanca en 1576 y era provincial en 1616-1617. En 1622 fue promovido a la sede de Nueva Cáceres en Filipinas, y después a la de Santiago de Cuba, donde murió en 1625. T. de Herrera, Historia, pp. 350 y 415. Más abundantes datos acerca de él véanse en: J. FERNÁNDEZ, OAR, Bullarium Ordinis Recollectorum S. Augustini, 
colegio de Alcalá. Durante aquel período conoció al beato por espacio de unos diez años. Después de haber sido dos veces provincial de la provincia recoleta de los agustinos, era ahora prior del convento de Madrid, situado en la acera que lleva su nombre.

El P. Alarcón había oído hablar de la veneración de altos personajes al beato y sabía también del permiso que había pedido a Felipe II para retirarse al convento del Risco, expresando este testigo la respuesta del rey a su manera. De la austeridad de su celda el P. Alarcón tenía noticia personal, habiendo ido dos o tres veces a ella "por orden del bendito Padre para que distribuyese en Alcalá, donde este testigo era estudiante colegial, unos librillos de devoción".

De la misma fuente de información, es decir, de sus visitas al convento de S. Felipe, procedía su información sobre el hecho de que el beato "estaba siempre en pie y quitando la capilla", hecho acerca del cual preguntó a los frailes y ellos le dijeron que el beato lo hacía así "por el respeto y la reverencia que tenía de Nuestro Señor, con quien hablaba".

A las demás preguntas no ofreció respuestas significativas, siendo su fuente de información la que hemos dicho.

\section{Declaración del P. Juan de Medina ${ }^{37}$}

Más detallada que la anterior es la declaración del P. Juan de Medina, religioso de 58 años, tres veces superior del convento de S. Pablo de los Montes (Toledo), del de Puentedeume (La Coruña) y del de Nuestra Señora del Pino en la provincia de Segovia. En el momento de sus declaraciones se dice conventual del convento de Casarrubios del Monte (Toledo) pero residente y presente en S. Felipe de Madrid.

El P. Medina dice haber conocido al beato Orozco desde el año 1580, en que tomó el hábito, hasta su muerte y le conoció bien pues le acompañó muchas veces cuando salía a predicar. Detalle original de este testigo es lo que había oído referir al difunto P. Gabriel Pinelo ${ }^{38}$, hombre de gran auto-

vol. I, ver indice de nombres en la p. 593; una breve reseña biográfica en: LUIS DE JESÚs, OAR, Historia general de los religiosos descalzos del Orden de los Hermitaños de S. Agustín, tom. II, Madrid 1663, pp. 59-61.

37. Proceso, pp. 723-730. La profesión del P. Juan de Medina, hecha en S. Felipe de Madrid el 31 de mayo de 1580 está registrada en el I Libro de profesiones de aquel convento. Cfr. Archivo Agutiniano 70 (1986) 63.

38. Acerca de este conocido predicador de Felipe II y profesor universitario véase los datos que ofrece T. de Herrera, Historia, pp. 287 y 348. Más recientemente se ha ocupado de él G. de Santiago Vela, Ensayo, vol. VI, Madrid 1922, pp. 318-320. Noticias personales y originales ofrece el P. Juan QUIJANO en sus Memorias, pp. 32 y 112-113 del extracto. 
ridad entre los agustinos, acerca de cómo Felipe II le pidió la bendición y un autógrafo cuando se disponía a ir a Portugal para anexionarse aquella corona.

De sus penitencias en parte tenía información propia y en parte de oídas de los otros religiosos. También tenía noticias acerca de su caridad para con los pobres, pero lo que él había visto personalmente era "hacer capotillos y grigüescos para los pobres de la portería". Enumera varios conventos donde el beato predicaba habitualmente, como eran los de Vallecas, la Magdalena en Madrid, las monjas de Pinto, las Descalzas Carmelitas, y el Hospital de la corte.

En cambio el milagro de haber recogido del suelo los cascos de una jarra que tenía escrito el nombre de Jesús, restaurándola el beato y dejándola sana, se lo oyó al difunto P. Alonso del Campo ${ }^{39}$, que es quien la dejó caer y quien contó cómo el P. Damián de la Serna, que acertó a pasar por allí en el momento del hecho, dio gritós anunciando el milagro, recibiendo del beato la orden de no decir tales cosas! Confirma que el beato no creía en los milagros de la monja de Portugal y sabe de la veneración que se prestó al beato Orozco con ocasión de su muerte; fue tal que "entraban con gran dificultad a ver su cuerpo por la grande apretura de la gente, a tocar los rosarios a sus manos y a sus pies", añadiendo que por la parte de fuera de la iglesia había unas escaleras para verle desde allí y que "los dueños de las escaleras ganaban muchos dineros".

De una gracia recibida por un Padre, que fue con él desde S. Felipe al colegio de Doña María de Aragón a ver al beato durante su última enfermedad, naturalmente tenía información propia. Era también de primera mano el detalle de haber asistido a la escena en que se dio el viático al beato, rodeado del rector y frailes del colegio, así como también de la condesa de Buendía y Doña María de Aragón, con la cual tuvo una curiosa conversación, en la que dio a enteder que estaba viendo a la Virgen.

\section{Testimonio de un agustino del convento de Chinchón}

Se había llegado a la altura de principios de septiembre de 1619 cuando se pensó en ofrecer la oportunidad de ser escuchados en el proceso a algunos testigos de Vallecas y de la villa de Chinchón. Para ello el postulador subdelegó sus facultades al P. Juan de Subijana, de la comunidad del colegio, y éste presentó al juez Gonzalo de los Ríos un memorial por el que pedía que,

39. La profesión del P. Alonso del Campo en S. Felipe de Madrid tuvo lugar el 21 de junio de 1580. Cfr. Archivo Agustiniano 70 (1986) p. 62. 
dado que el juez estaba ocupado en cosas del servicio de Su Majestad, delegase para la audición de estos testigos al notario Juan de Alegría. Así se hizo con auto firmado en Madrid el 9 de septiembre de 1619.

Entre los testigos que se oyeron en esta ocasión hay que recordar al agustino P. Diego Gutiérrez de Ventimillas ${ }^{40}$, que dijo tener 66 años de edad y haber conocido al beato Orozco por espacio de 14 años.

Este Padre habia oído de labios del beato las circunstancias de su nacimiento y por qué se le había puesto el nombre de Alonso; "y nació en jueves", añade el declarante.

De haberle acompañado mucho en sus predicaciones sabía este testigo la veneración que le tenía la gente, que casi no le dejaba pasar cuando iba por las calles. Dígase lo mismo del rey Felipe II, que un día fue incluso a visitarle al convento de San Felipe y le preguntó cómo estaba. Y como el beato no hubiera oído bien la pregunta y preguntara él a su vez al rey cómo estaba, el rey se la hizo por segunda vez, cosa que no acostumbraba nunca.

De su abstinencia recuerda un episodio cuando el beato no quiso recibir una comitiva de 24 pajes del Prior Don Antonio, Comendador Mayor de la Orden de San Juan, que traían dos platos cada uno de parte de su amo, precedidos de un mayordomo. A los cuales el beato mandó que lo llevaran a la gente pobre de los suburbios. Otros muchos detalles pudo observar este religioso acerca de su austeridad en la habitación, en cuyo contexto narra un desfallecimiento que tuvo el beato de pura debilidad, que obligó a llamar a los médicos.

Narra así mismo la visita que le hizo un día Hernando de Vega, presidente del consejo de Indias y obispo de Córdoba, el cual le metió en un aprieto cuando le dijo que quería cenar con él, pues el beato o no lo hacía o era tan frugal que le daba vergüenza que dicho señor le acompañase. A la escena estuvo presente el difunto P. Gabriel Pinelo, prior de S. Felipe, que tuvo una conversación muy graciosa con el beato, el cual se maravillaba de que no bastara para cenar lo que él pedía se comprase con un "cuartillo" que le entregaba para ello... La cosa edificó mucho al alto dignatario.

Graciosa fue también la escena que dice haber presenciado este testigo, a saber, cómo sufriendo mucho el beato por los callos de los pies, vio una vez cómo le visitaba el Card. Quiroga ${ }^{41}$, con el licenciado Peña ${ }^{42}$ y otros criados

40. Proceso, pp. 740-756.

41. Para una información general sintética acerca del Card. Gaspar Quiroga y Vela (15121594), natural de Madrigal de las Altas Torres (Avila), amigo del beato Orozco y de los agustinos en general, véase: Diccionario de Historia Eclesiástica de España, vol. III, Madrid, CSIC, 1973, pp. 2041-2042 (A. Orive).

42. Es probable que se trate aquí de Francisco Peña, presentado por Felipe II para la Rota Romana, donde trabajó bastantes años y consiguió gran fama de canonista. Le dedica una breve reseña el mismo Diccionario de Historia eclesiástica de España, vol. III, p. 1957. 
del cardenal; y como los médicos habían ordenado rascarle las plantas de los pies para que el beato pudiera dormir, así lo hicieron estos ilustres huéspedes, haciendo notar el licencia Peña el suavísimo olor -“de cielo y de ángeles"- que despedían aquellos pies.

Más o menos conocidos son los detalles que narra de su caridad, predicación, observancia de las Constituciones de la Orden, etc. Lo que no habíamos leído en las declaraciones de otros testigos es el haber escrito el beato un libro titulado :"Felipe y Orozco", escrito para la instrucción cristiana de un turco que le envió su maestro para que le enseñase, el cual efectivamente se bautizó, se casó en Madrid e hizo luego muchos viajes a Turquía para rescatar cautivos.

Bella también es la escena, narı ada por este testigo, que la presenció, de la ida del beato a palacio para decir los evangelios al príncipe D. Diego ${ }^{43} \mathrm{y}$ cómo el conde de Barajas ${ }^{44}$, no apercibiendo que se trataba del beato y de su compañero, los mandó echar fuera de la habitación del príncipe. Advertido después del engaño, el conde les mandó entrar y arrodillado pidió escusa al beato. En la mima ocasión el futuro rey Felipe III, cuando no tenía más que ocho meses, pidió al beato Orozco la mano y se la besó, estando presentes los condes de Barajas, de Uceda y la condesa de Paredes. Narración a la cual añade el declarante dos curaciones milagrosas, entre las muchas que hizo el beato en vida y después de la muerte.

En el tema de la correa del beato usada con ocasión de partos, es de agradecer que este testigo recordara el episodio, vivido por él, según el cual el beato fue llamado por el duque de Olivares ${ }^{45}$ para que dijera los evangelios a su mujer antes del parto y cómo todo resultó bien. Nos imaginamos que se trata aquí del nacimiento del que más tarde fue gran valido de Felipe IV ${ }^{46}$, y para quien su padre había pedido que el beato le dijera los evangelios "para que Dios le hiciera bueno y todo sucediese bien".

43. Se trata del príncipe D. Diego, hijo de Felipe II, nacido en 1575 y muerto con siete años en 1582, después de haber sido ya jurado como heredero de la corona en 1579. Algunos datos sobre él pueden leerse en: Luis FERNANDEZ Y FERNANDEZ DE RETANA, España en tiempo de Felipe II (1556-1598), vol. II (= Historia de España bajo la dirección de Ramón Menéndez Pidal, XIX/2), Madrid 1966, pp. 288, 308, 344 (retrato), 743.

44. Por la época de este episodio cubría el alto cargo de Presidente del Consejo de Estado, pero fue destituido de él por Felipe II en 1591, por consejo de su confesor el dominico P. Chaves, por razones que no son bien conocidas. Cfr. Ibid., pp. 749-750.

45. D. Enrique de Guzmán (1540-1607), segundo conde de Olivares, que desempeñó varias misiones diplomáticas para Felipe II, el cual le mandó en 1582 como embajador a Roma. Cfr. Diccionario de historia de España, Madrid 1952, Revista de Occidente, vol. I, pp. 1300-1301.

46. D. Gaspar de Guzmán (1587-1645), tercer conde, llamado generalmente el condeduque de Olivares. Sobre él en síntesis véase: Diccionario de historia de España, vol. II, pp. 696702. Es clásica la biografía de Gregorio MARAÑón, El conde-duque de Olivares o la pasión de mandar, 3 ed., Madrid 1952. 
Después de haber dicho que descubrió los engaños de Pirola -en algunas deposiciones se le llama Piedrola-- y de la monja de Portugal, narra este Padre el episodio en que le presentaron una mujer para que le sacara los espíritus, a lo que él replicó que no tenía espíritus sino que estaba loca, lo cual se comprobó después.

Al contenido del artículo 46 este testigo respondió que lo sabía por habérselo contado el P. Hernando de Rojas -confesor del beato- y el P. Legarda ${ }^{47}$. Al mismo testimonio del P. Rojas se apela en su respuesta al artículo 56, que era el último.

Digna de ser narrada es la historia del carretero que llevó en una ocasión al beato a Talavera, para asistir al capítulo de sus monjas. El cual, una vez que regresó a Madrid y se apeó el beato, pero todavía en presencia del P. Gutiérrez de Ventimillas, protestaba que aquel hombre era un santo y que, de no estar casado, se hubiera hecho fraile sólo para servirle.

Evidentemente el P. Ventimillas tenía buena memoria y era depositario de muchas anécdotas que creyó útiles para confirmación de la santidad del beato, por lo que había pedido ser oído aunque se encontrara en el convento de Chinchón, donde moraba.

\section{Los PP. Cristóbal de Fonseca y Alonso de Soto}

Siendo conventuales en S. Felipe en el momento en que se instruía el proceso, fueron llamados también a declarar el P. Cristóbal de Fonseca ${ }^{48}$ y el P. Alonso de Soto ${ }^{49}$. El primero de ellos, tan conocido por su tratado "Sobre el amor de Dios", que mereció ser citado por Cervantes en el prólogo de su inmortal novela, tenía entonces 65 años y dijo haber conocido al beato sólo durante diez meses. En efecto, no es mucho lo que aporta este testigo al contenido del proceso: respondió únicamente a los artículos $8,11,15,20,21,34$ y 35 pero no aportó ningún detalle de relieve, fuera de que, habiendo entrado una vez a ver su celda el dominico P. Lorenzo de Figueroa, obispo de

47. Que el P. Bartolomé de Legarda vivía por estos años en S. Felipe se evidencia por el libro de profesiones que cubre este período. Cfr. Archivo Agutiniano 70 (1986) pp. 60, 62, 65, 66.

48. Proceso, pp. 796-800. Los datos relativos a su profesión (Toledo, 8 de febrero de 1566) pueden verse en: Ignacio ARAMBuru, "Las profesiones religiosas del convento de Toledo. Libro I (1495-1566)" en: Archivo Agustiniano 67 (1983) 355-381; la profesión de este religioso en la p. 381. Sobre su importante producción literaria véase: Gregorio de SANTIAGo VELA, Ensayo..., vol. II, Madrid 1915, pp. 621-639.

49. Proceso, pp. 807-817. Su profesión en S. Felipe de Madrid tuvo lugar el 1 de mayo de 1673. Cfr. Archivo Agutiniano 70 (1986) p. 56. 
Sigüenza ${ }^{50}$, salió asombrado de la aspereza de su cama "y por ser el dicho obispo muy devoto, mostró un linaje de envidia y de ternura en los ojos de haberle visto", añadiendo que suponía que había conseguido verla un poco por la fuerza, "pues el bendito Padre Orozco a nadie la dejaba ver".

Más rica es la declaración del P. Alonso de Soto, que tenía entonces 50 años y dijo haber conocido al beato los últimos diez años de su vida.

Original de su declaración es el detalle de que yendo un día en la procesión del Corpus por "mayor" de la misma el Presidente de Castilla, mandó llamar al beato para que fuera a su lado, y que éste se disculpó diciendo que "no podía ir sino con su Religión". Confiesa el P. Soto ser uno de los que espiaban al beato para ser testigo de sus penitencias, pero "algunas veces que (el beato) le veía que andaba acechando, le reñía porque le dejase". Sabe también que, con ocasión de la enfermedad de que murió, le llevaron al colegio de Doña María de Aragón el Cristo que estaba sobre el facistol del coro en S. Felipe, del cual se decía que había hablado al beato. Tal crucifijo después de su muerte se quedó definitivamente en dicho colegio. El episodio de que Cristo le había dado de comulgar lo narran algunos testigos y éste lo hace con muchos detalles, indicando que fue una víspera del Corpus y que él lo sabía por habéselo oído contar al confesor del beato, el P. Hernando de Rojas.

Conoce también este testigo el episodio de las tijeras caídas al suelo que hizo desaparecer el diablo, y fue testigo presencial del episodio en que el beato cortó las partes laterales de su hábito para dar la tela a un pobre, andando el beato por el convento como metido en un costal. Era prior de S. Felipe el P. Pinelo, el cual le dijo que no volviera a hacerlo y que, cuando no tuviera qué dar a los pobres, se lo dijera a él, que él le daría con qué hacer limosna.

El P. Soto confiesa haber sido "aficionado del dicho beato", por lo cual acudió muchas veces a su celda, encontrándole siempre ocupado componiendo libros. Original también la narración de la curación que le había hecho a él con ocasión de la desgracia que tuvo en el viaje de regreso de Segovia, adonde había ido a "ordenarse de epistola", cuando el macho en que viajaba le tiró al suelo y le mancó. Conocía también por narración del P. Legarda los dos milagros obrados el día de la muerte del beato, y la aparición del mismo

50. Lo fue durante el período 1579-1605. Era de la noble familia de los condes de Feria. Véase el capítulo que le dedica el P. Toribio Minguella y ARNedo, OAR, Historia de la diócesis de Sigüenza y sus obispos, vol. II, Madrid 1912, pp. 280-296. 
al piadoso agustino P. Juan de Castro ${ }^{51}$, arzobispo de Bogotá y gran amigo del beato, en el momento de su muerte.

Mencionado por muchos testigos y también por éste es el conocimiento que el beato tenía de la falsedad de la monja de Portugal y narrada por éste y alguno más la porfía con que los frailes de S. Felipe se disputaban para reliquia los cabellos del beato cuando había corte de pelo en la comunidad. Confirmado también el episodio de los devotos que se acercaban a tocar objetos en el cuerpo del beato el día de su muerte, cosa que este testigo bien conocía por haber sido él mismo el encargado de llevar a cabo esta piadosa tarea.

\section{Las declaraciones del P. Juan Becerra ${ }^{52}$}

El P. Juan Becerra, conventual de S. Felipe, de 57 años de edad, sólo conoció al beato Orozco durante tres años. Ofrece de original el detalle de haber quitado del cuerpo del beato, el día de las traslación de la vieja a la iglesia nueva, un dedo que había sido casi separado de su cuerpo por algún devoto, y habérselo dado a la duquesa de Feria, Doña Francisca, abuela de D. Tomás de Figueroa, actual duque de Feria ${ }^{53}$, la cual lo llevó a Zafra y lo depositó en un convento de monjas que ella había fundado. El P. Soto pudo hacer esto por ser estudiante en el colegio de Doña María de Aragón cuando tuvo lugar la traslación del cuerpo de una iglesia a otra.

Confirma lo de los callos que molestaban al beato en los pies, narrado por su confesor el P. Rojas. Es, en cambio, un dato original el que refiere él de haber llamado el beato, durante su propia enfermedad, a sus pobres para que le pusieran las manos en la cabeza, con lo que se sintió mejorado. Así lo refería, según este testigo, el difunto Baltasar Carpinera. Muy completa resulta también la lista de las obras del beato que él conocía y que especifica respondiendo al artículo 33 del interrogatorio. Y como esta lista aparece casi igual y por el mismo orden en varios otros testigò agustinos, es lícito pensar que, con occasión del proceso, se confeccionó una, que fue pasando de mano

51. Este religioso, también célebre predicador y arzobispo de Bogotá, hizo su profesión en el convento de Toledo el 22 de agosto de 1565 y el acta contiene anotaciones muy curiosas. Cfr. Archivo Agustiniano 67 (1983) p. 380. Tiene su lugar en el repertorio del P. G. de Santiago VeLA, Ensayo, vol. I, Madrid 1922, pp. 675-676. Para la biografía de este arzobispo, escrita por el P. Castillo, véase: ibid., pp. 652-653.

52. Proceso, pp. 824-835.

53. Breves indicaciones sobre los duques de Feria en: Diccionario de historia de España, vol. I, p. 1103, y en la Enciclopedia "Espasa", vol. 23, p. 714 
en mano entre los que iban a ser llamados a declarar ante el juez de esta causa.

Como milagros recuerda el del alguacil Alonso Núñez de Cos y el de María de Oñate, curada el día de las traslación del cuerpo, estando este testigo como estudiante en el colegio de Doña María de Aragón, así como uno de los milagros obrados con su correa. De las fundaciones recuerda la del convento de la Magdalena, en torno a lo que ofrece algún detalle original, y la del colegio de Doña María de Aragón, cuya primera piedra se puso en la fiesta de S. Agustín, siendo el beato su primer rector.

Ultima novedad de su declaración es la enumeración de los religiosos que asistieron a la traslación del cuerpo en 1603. Fueron ellos los PP. Hernando de Rojas, rector del colegio, Agustín de la Mota, prior de S. Felipe, Juan de Arenas ${ }^{54}$, prior en 1619 del convento de Valladolid, Cristóbal de Fonseca, Agustín Fernández, "y otros Padres graves", añade el testigo sintetizando.

\section{El P. Juan de Soto y sus declaraciones ${ }^{55}$}

Llenas de interés aparecen las declaraciones de este religioso, a quien se presenta como "predicador de la Orden de San Agustín, conventual del colegio de Alcalá, residente al presente en esta corte", el cual dice ser de 55 años y haber conocido al beato durante doce.

Interesantes son los detalles que da acerca de sus predicaciones, dice las cuales dice que las hizo muchísimas veces en la capilla real y añade: "los cuales (sermones) este testigo tiene de su misma letra del dicho Venerable Padre, con el año mismo que se predicaron" y que "los reyes le llevaban a él y no a otro ninguno a decir los evangelios al príncipe heredero y a otros infantes estando enfermos, y que les levantaba la ropa de la cama y les daba a besar la mano".

Sabe que, como dormía tan poco el beato, "los prelados de S. Felipe mandaban a los que tañían la campana del alba no tañesen con campana mayor poque al dicho Padre no le hiciesen ruido". Da numerosos otros detalles sobre su celda, cama y ropa, añadiendo que entró a hurtadillas alguna vez pero que no pudo verla demasiado bien. Asegura que le conoció en cuatro celdas diversa, tan malas, que las de los novicios "eran muy mejores".

54. Este religioso profesó también en S. Felipe de Madrid el 28 de agosto de 1575. Cfr. Archivo Agustiniano 70 (1986) p. 59. Una pequeña reseña bio-bibliográica de él en: G. de SANTIAGo Vela , Ensayo, vol. I, Madrid 1912, pp. 198-199.

55. Proceso, pp. 853-870. 
"Todo lo cual vio este testigo las veces que pudo metiendo la cabeza por la puerta".

Confirma otros detalles acerca de su abstinencia prodigiosa y cómo el prior, siendo ya el beato viejo y debilitado, le ordenó hacer colación. Confirma la asistencia continua al coro, su costumbre de estar siempre en pie y añade que, aunque los otros religiosos "estaban al sol en coversación, él por no parecer que se extrañaba, estaba con ellos cosa de medio cuarto de hora, poco más o menos, siempre en pie", por reverencia a Dios, en cuya presencia estaba siempre.

Este religioso le ayudó muchas veces a Misa y fue testigo de su devoción en ella; recuerda además lo de la comunión dada por Cristo mismo, con detalles especiales procedentes de su confesor el P. Rojas. Confirma lo de los callos que le molestaban y añade que no quería y tenía por superfluo el alivio que entonces le daba Doña María de Aragón "que está en gloria".

Le vio confesarse diariamente antes de celebrar y que estas confesiones eran largas, lo que extrañaba no poco al joven novicio que le iba a ayudar a Misa. Tocándole por su ancianidad y autoridad el sitio junto al prior en el coro, se colocaba en cambio en un rincón, y a este novicio le extrañaba que se lo permitieran. Confirma que se levantaba a tocar el órgano, especialmente los sábados, en las Misas de Nuestra Señora, y añade que predicaba sermones aunque no hubiera sino pocos oyentes y predicaba los sermones que otros predicadores no querían.

Sabe que hacía limosnas en la sacristía a viudas que venían a la hora de la Misa, "porque en otra parte no hablaba a ninguna mujer", y empleaba todo su salario de predicador real en pobres, encarcelados y "niños chiquitos, a quien(es) también hacía limosnas de capotillos y mantillas", pidiendo dinero a otras personas cuando su salario no le alcanzaba.

De su recato con las mujeres pudo testificar este testigo cómo, advertido por otros para que le observase, vio el arte con que "se daba la vuelta, volviendo casi los hombros" para no mirarlas a los ojos. Respondiendo al artículo 33, relata la amplia lista de libros suyos que le eran conocidos, pero añade que debió de escribir otros más, especialmente uno "que debió dejar manuscrito, el cual intitulaba Grito del pecador, que estaba escribiendo cuando le visitaron en su celda dos novicios, uno de los cuales era él. Despues de lo cual explica que tenía varios cuadernos autógrafos del beato, los cuales entregó allí mismo al juez de la causa para que los incluyeran en ella y se conservaran como reliquias.

De los milagros recuerda el de la jarra dejada caer por dos novicios y recompuesta por el beato, el de una muchacha que sus padres daban por muerta y a quien él pidió para el monaterio que estaba fundando en Talava- 
era -donde ella vivía todavía en el momento del proceso, en el cual testificóademás de la conversión y reconciliación con su mujer del padre de dicha monja y la curación en trance de muerte de una hermana del agustino $P$. Alonso del Campo, ya difunto en 1619.

En el terreno de las profecías recuerda lo de Pirola y la monja de Portugal, de quien el propio padre de este testigo, el licencia Soto, tenía un paño con mucha devoción; el cual presentado al beato, repitió sobre ella el juicio que ya hemos indicado otras veces.

Muy personales eran las noticias que este religioso tenía, como testigo que fue de vista, sobre las fundaciones de los conventos de la Magdalena y de la Visitación. El asistió, cuando tenía nueve años, a la procesión que se hizo para la inaguración del convento de la Magdalena, en la que tomaron parte religiosos ancianos de la provincia, entre ellos el P. Pinelo, y vio cómo "llevaban de la mano" a las religiosas y cómo el beato Orozco "llevaba de la mano" a la priora.

Pasando por alto algún detalle de menor importancia, queremos destacar lo que refiere sobre el traslado del cuerpo del beato de una iglesia a otra. Acerca de lo cual dice haber preguntado a su padre, que era médico y estuvo presente a todo y tocó el cuerpo del beato, si era verdad que estaba fresco, y su padre le dijo que sí. Precisa que sólo se veían alunos agujeros en las canillas, causados por la corrupción del hábito ajeno que le pusieron para la sepultura, pues el suyo lo guardaron para reliquias. Añade que el cambio del hábito fue cosa del P. Hernando de Rojas, el cual cuando el traslado se dolía de no haberle puesto el propio, y añade que la túnica propia del beato estaba tiesa y dura como si se acabara de sacar del comercio. Narra así mismo cómo un religioso atrevido quiso quitarle un dedo y no lo consiguió por más esfuerzos que hizo. Ya explicamos arriba quién fue el que terminó de quitárselo y cómo se lo dio a una noble y piadosa dama, que lo depositó en un convento que había fundado en Zafra. Por último, recuerda cómo se hizo acta oficial del traslado por autoridad del Ordinario y cómo algunos médicos dijeron que les parecía fuera de lo natural la conservación de aquel cuerpo.

Finalmente, otro detalle nuevo: el beato habría dicho varias veces que le enterraran junto a la pila del agua bendita y pusieran el siguiente letrero: “¡Fieles, rogar por este pecador!”. Bien diverso era el que le pusieron con ocasión del traslado de su cuerpo, en el que se daba gloria a Dios por su santidad. Tan conocida y predicada era de todos, que este Padre confiesa no haber oído en toda su vida llamarle por el propio nombre, sino con la expresión: "el santo Orozco" y recuerda el lamento del P. Pinelo, prior de S. Felipe, de tener que perderle cuando el beato se fue a vivir al colegio de Doña María de Aragón. 
Este es el precioso testimonio de un Padre que le había conocido y tratado mucho y le profesaba una devoción sin límites.

\section{Otro precioso testimonio: el del P. Agustín Fernández ${ }^{56}$}

No menos bella es la declaración del P. Agustín Fernández, "predicador y colegial" del colegio de Doña María de Aragón y de 44 años de edad en el momento del proceso. Dice haber conocido al beato durante tres años, pero sus recuerdos eran bastante abundantes y particularizados.

Este Padre había oído al P. Hernando de Rojas cómo habían estado una vez en la habitación del beato, en el colegio de Doña María de Aragón, tanto el rey Felipe II como los príncipes; lo que no sabía de seguro era si habían ido "sólo a verle o al dicho colegio". Curiosa la obsevación de que él le conoció de novicio y que los vestidos que llevaba eran "de fresa blanca", que se vendían muy baratos -él tenía algún trozo- y que siempre le vio vestido así y que "el hábito (estaba) hecho al modo de los agustinos recoletos, y de aquel paño el blanco, y el negro no se acuerda de qué paño".

Después de ponderar la asiduidad al coro del beato no obstante el calor "aunque el coro estaba incómodo y no como está ahora", recuerda que el beato se rebajaba a enseñarle a él, que era novicio, "como había de cantar". Seguidamente entregó al juez del proceso un texto del santo Fr. Juan de Castro, arzobispo de Bogotá, y otro hallado entre los del P. Hernando de Rojas, para que fueran incluidos en el proceso. Ambos eran sumamente laudatorios del beato y se transcribieron literalmente en las actas del proceso pues eran breves. Abundantes fueron las explicaciones que dio sobre cómo vinieron a sus poder estos papeles. A todo lo cual siguen los testimonios del aprecio que de él tenían el Card. Quiroga y Doña María de Aragón y los oficios de presentado y predicador -además de escritor- que tuvo en la provincia.

Después de precisar que era este testigo quien tenía a custodia en el colegio de Doña María de Aragón el crucifijo que habló al beato en el coro de S. Felipe, asegura que escribió las "Confesiones" a instancia del Card. Quiroga, y pasa luego a hablar de los escritos del beato respondiendo al artículo 33. Entre ellos menciona -y después hizo entrega de él al juez del proceso- uno autógrafo, donde el beato, a instancia de algunos devotos suyos, hizo una relación de todo lo que había escrito. Esta relación era inédita y

56. Proceso, pp. 888-904. La profesión de este religioso, hecha en S. Felipe de Madrid el 1 de enero de 1590, está registrada en el I Libro de profesiones de aquella casa. Cfr. Archivo Agutiniano 70 (1986) 69. 
estaba en latín. La relación comenzaba por los escritos latinos y proseguía con los escritos "en romance".

Tenía este religioso también en su poder la licencia de Felipe II para la impresión de esta "Tabla alfabética", licencia dada en El Escorial el 28 de mayo de 1588 , junto con la licencia del provincial agustino P. Antonio Monte ${ }^{57}$, dada en Valladolid el 13 de mayo del mismo año. Seguidamente describe dos cartas autógrafas del beato a Doña María de Aragón relacionadas con la fundación del colegio y una al marqués de Tábara en tres hojas, para animarle cuando abandonó las cosas del mundo para retirarse a la soledad.

Recuerda además uno de los milagros obrados el día de la tráslación y sobre todo certifica haber sido él quien, durante el traslado, quitó al beato la correa que tenía para ponerle otra y quien dijo al rector del colegio quién se había quedado con ella, al cual se pidió después y la entregó; de modo que podía testificar este testigo que la correa que se llevaba a los enfermos y hacía tantos prodigios era verderamente la que el beato había tenido en vida y desde su entierro hasta el momento del traslado del cuerpo.

Este testigo menciona a las personas principales que asistieron a dicho traslado -mencionadas ya por otros testigos- pero a las cuales añade él al deán de Salamanca, D. Jerónimo de Chiriboga. Muy personal es el recuerdo siguiente: "no se hallaron las llaves de las puertas grandes para meter el cuerpo en el ataúd, el cual no cabía por la puerta pequeña, y por no maltratarle, sacó este testigo el cuerpo y le metió en la iglesia nueva sin el ataúd, y luego metieron el ataúd solo de medio lado".

Este fue el testimonio detallado y original del P. Agustín Fernández, que añade tantos datos a los que ya habían dicho otros testigos acerca de la vida, muerte y traslado de los restos del beato.

\section{Los PP. Juan de Lerma, Juan Gutiérrez y Antonio del Castillo}

Mucho más pobres que las que acabamos de ver resultan las declaraciones de estos tres Padres, que fueron oídos entre el 24 de diciembre de 1619 y el 8 de enero de 1620.

El P. Juan de Lerma ${ }^{58}$ era persona de autoridad en la provincia; era maestro en S. Teología, había sido definidor y rector del colegio de Doña María de Aragón y en la actualidad era prior del convento de S. Felipe. Tenía 50 años de edad y había conocido al beato solamente dos o tres años.

57. Algunas apreciaciones sobre este provincial las formula el P. Juan QUIJANO, Memorias, p. 52 del extracto.

58. Proceso, pp. 919-922. 
Su declaración versa solamente sobre el artículo 20, en el cual refiere la comunión dada al beato por un ángel en cierta fiesta del Corpus Christi, según la versión del P. Hernando de Rojas, a quien el mismo beato se lo confesó luego. Alude también a una aparición de la Virgen en la celda del colegio de Doña María de Aragón, donde murió, según información del mismo confesor del beato.

El P. Juan Gutiérrez ${ }^{59}$, de 62 años de edad y que había conocido al beato durante 16 años, tiene más originalidad por su historia externa que por sus declaraciones. De él se dice que era presentado en $\mathrm{S}$. Teología y que había sido dos veces comisario del rey a las "Indias Filipinas", prior, definidor y visitador de aquellas provincias, de donde había venido al capítulo general como representante de dichas provincias. En el momento de declarar en el proceso era "predicador en este convento de S. Felipe de Madrid y procurador y administrador general de hacienda y tesoro del bienaventurado Santo Juan de Sahagún para su canonización, y confesor de las damas de palacio" ${ }^{60}$.

Responde sólo a los artículos 8, 34 y 37 del interrogatorio, confirmando que se le llamaba normalmente "el Santo Orozco", a lo que añade: "y no sabían otro nombre de él". Refiere que el beato le curó de una enfermedad, estando en el convento de S. Felipe, mediante la imposición de las manos y asegurándole que no moriría de aquella enfermedad. Más interesante resulta la información que dice haber oído un día, estando con otros religiosos en un claustro del convento, donde el P. Juan de Castro, futuro arzobispo de Bogotá, confesor y amigo íntimo del beato, refería cómo estando él un día en el coro sin saberlo el beato Orozco, le oyó decir en voz alta: “¡Ah, Señor, esta canal!; ah, Señor, esta canal!...", resultando que fue justamente aquel día cuando tuvo lugar el desastre de la Armada Invencible. De donde infirieron todos que había tenido revelación de aquel suceso y pedía al Señor remedio. No ofrece otros datos este religioso, pero el último detalle que acabamos de referir es muy apreciable.

El último del trío anunciado es el P. Antonio del Castillo ${ }^{61}$, de 52 años y conventual de S. Felipe, donde era predicador. Dice no haber conocido

59. Proceso, pp. 922-925. Aparece como prior en el convento de S. Felipe de Madrid entre el 23.II.1578 y el 4.VI.1583, fechas en las que firma diversas profesiones religiosas. Cfr. Archivo Agustiniano 70 (1986) 61-62.

60. A juzgar por los datos que ofrece sobre su estancia en Filipinas y participación en capítulos generales, se trata aquí del P. Juan Gutiérrez que asistió a los capítulos generales de 1591 y 1602, del que se ofrecen pocos datos en: Elviro J. PÉREZ, Catálogo bio-bibliográfico de los religiosos de la provincia del Smo. Nombre de Jesús de Filipinas, Manila 1901, p. 63.

61. Proceso, pp. 939-942. Sobre este Padre véase lo dicho en la nota 49, donde mencionamos su biografía del arzobispo de Bogotá Fr. Juan de Castro. 
nunca al beato por haber estado siempre fuera de Madrid desde que tomó el hábito en la provincia de Castilla-Andalucía, pero sí que había oído muchas cosas del P. Juan de Castro. Declaró únicamente sobre el artículo 34, donde narra la supuesta aparición del beato Orozco al P. Juan de Castro poco antes de su muerte, estando presentes varios seglares y religiosos junto al lecho del enfermo. El beato le habría dicho que "iba a buen lugar", como lo colige este testigo por una frase que el arzobispo moribundo le dijo a él uno de aquellos últimos días de su vida. El cual le habría confiado también la queja de que la Orden era responsable de un importante descuido en no mover las cosas para que el beato Orozco fuera canonizado.

La queja, pronunciada en 1611 cuando este arzobispo moría, tenía su fundamento, pues habían pasado ya 20 años desde la muerte del beato Orozco y deberían pasar un total de 28 antes de que se abriera el proceso que estamos comentado. Ello ocasionó que, de la vida de un varón que murió con 91 años, los testigos más informados no pudieran ilustrar más que los últimos veinte de su vida. Pero, eso sí, lo hicieron exhaustivamente, como estamos viendo.

\section{Aval en favor del P. Hernando de Rojas}

Vimos ya que el P. Agustín Fernández presentó al juez de la causa algunos escritos del beato y también uno del P. Hernando de Rojas en que trataba de los favores recibidos de Dios por el beato Orozco, escrito de la mano del mismo P. Rojas. Con el fin de dar valor jurídico a este escrito y acreditar las cualidades morales del autor, el postulador de la causa P. Herrera, a un cierto momento pidió que se oyera con este fin a dos testigos que presentaba. Eran los PP. José de Castro ${ }^{62}$ y Agustín Antolínez ${ }^{63}$. El juez lo concedió mediante auto firmado en Madrid el 12 de junio de 1619. El escrito del P. Rojas, que llevaba como título "Vida de nuestro Padre", se transcribe a continuación del auto recién mencionado.

Del P. José de Castro se dice que era colegial del colegio de Doña María de Aragón pero no se da su edad. El testigo dice conocer bien la letra del P. Rojas y alaba su vida piadosa y sus virtudes. También del P. Antolínez se dice que era colegial del mismo colegio, sin añadir uno sólo de los muchos títulos y méritos que tenía, como el de haber sido provincial y ser profesor universitario en Salamanca. Testimonio semejante al anterior ofrece el P.

62. Proceso, pp. 955-957.

63. Proceso, pp. 957-959. 
Antolínez acerca de su conocimiento de la escritura del P. Rojas y de sus virtudes.

Como estas dos declaraciones servían sólo de aval del P. Rojas, se omitió toda otra noticia, pero el P. Antolínez sería llamado a declarar sobre el beato en el proceso que se abrió en Salamanca, en el cual se contienen tal vez las mejores noticias acerca del beato, puesto que procedían de los Padres más ancianos y cualificados de la provincia, varios de ellos profesores en aquella universidad.

\section{Los PP. Matías de Ontiveros y Andrés de Urosa}

El 16 de marzo de 1620 era escuchado por el juez del proceso el P. Matías de Ontiveros ${ }^{64}$, conventual de $\mathrm{S}$. Felipe, de 57 años de edad, el cual había conocido al beato Orozco durante 7 años antes de su muerte.

Este religioso recuerda una escena relacionada con una visita del Card. Quiroga al beato durante su última enfermedad, en la cual Doña María de Aragón, presente a la escena, pidió al cardenal que le echara su bendición, a lo cual se negó él diciendo que más valía la bendición del P. Orozco, y vio cómo ambos, el cardenal y Doña María, le insistían para que les bendijese; cosa que el beato hizo por pura importunación. Después de lo cual trajeron un Misal al Card. Quiroga para que leyera sobre el enfermo los evangelios. Este Padre confirma lo que ya sabemos acerca de cómo el beato consumía sólo la mitad de la escasa comida que una vez al día se le llevaba, y sabe que el pobre a quien daba la otra mitad se llamaba Coloma.

Otro episodio que narra es que, estando muy malo de la última enfermedad, pedía el beato con insistencia al P. Rojas y a este testigo que le vistiesen para ir a hacer una visita al Smo. Sacramento, considerándose indigno de que el Señor tuviera que venir a visitarle a él. Aunque no querían contentarle por su flaqueza, dada su insistencia empezaron a vestirle, pero se les desmayó a causa de su debilidad y tuvieron que volverle a la cama.

Otra particularidad que conocía el P. Ontiveros era la división que el beato hacía del estipendio que recibía como predicador del rey, del cual una tercera parte la daba al monasterio de agustinas que él había fundado en Talavera, otra tercera parte a los pobres y la última al convento de $\mathrm{S}$. Felipe. $\mathrm{Y}$ diciéndole el prior de $\mathrm{S}$. Felipe que podía dar a los pobres también la parte destinada al convento, él respondió que ya que él "no ayudaba ni servía a la comunidad, que recibiese el convento aquella parte para su sustento".

64. Este religioso profesó en S. Felipe de Madrid el 19 de febrero de 1586. Cfr. Archivo Agustiniano 70 (1986) 65-66. 
Por lo demás, habiendo sido compañero del P. Alonso de Soto en el viaje de regreso de Segovia, adonde habían ido a ordenarse de diáconos, fue testigo del accidente que sucedió a aquel religioso y supo después cómo el beato le había curado.

A propósito de la monja de Portugal, narra el episodio en que el contador mayor Peribáñez quería darle a besar una supesta reliquia de dicha monja. El beato lo rehusó y durante la confesión que esa persona hizo con el beato le entregó la presunta reliquia; añadiendo que después el beato mandó a este testigo que la quemara. Cuando Peribáñez le dijo que todos la tenían por santa, repondió que también habían tenido por tal a Sor Magdalena de la Cruz, la llamada "monja de Córdoba" ${ }^{65}$, cuya falsedad ya se había descubierto. La de la monja de Portugal se descubrió al año siguiente, precisa el $\mathbf{P}$. Ontiveros.

Muy interesantes son otros detalles relacionados con su última enfermedad y muerte, pues el P. Ontiveros dice haber sido su enfermero. Por ello sabía cómo tres o cuatro días antes de la muerte, creyendo el P. Rojas que había llegado el momento, se lo hacía presente al beato, el cual respondió: "en jueves nací y en jueves será Dios servido de llevarme". Sucedió en efecto su muerte el jueves siguiente. Muchos otros detalles narra sobre el momento de la muerte y sepultura, añadiendo cómo el P. Rojas conservó unos zapatos del beato, que había llevado durante 14 años. En suma, se trata de una preciosa declaración que arroja amplia luz sobre momentos significativos de la vida del beato, no manifestados por otros testigos.

Menos interés tienen las declaraciones del P. Andrés de Urosa ${ }^{66}$, conventual de $\mathrm{S}$. Felipe, de 40 años, el cual dice no haber conocido al beato.

$\mathrm{Su}$ declaración se limita a atestar cómo el P. Fráncisco de Mondéjar -ya vimos que en otro contexto se le llama hermano-gran siervo de Dios y muy amigo del beato, le había asegurado que la pitanza que el beato daba a los pobres y que dicho religioso bajaba de la habitación del beato Orozco a la portería, se multiplicaba en favor de los mismos pobres.

\section{Tres declaraciones en abono de varios religiosos que habían declarado en} este proceso

El 1 de junio de 1620 el postulador P. Herrera presentó en el tribunal a tres religiosos del convento de $\mathrm{S}$. Felipe en abono de varios de los religiosos

65. Sobre esta monja, condenada por el tribunal de la inquisición de Córdoba, la cual abjuró el 3 de mayo de 1546, véase: Alvaro HuERGA, Historia de los alumbrados, vol. I: Los alumbrados de la alta Andalucía, 1575-1590, Madrid 1978, pp. 16-22.

66. Profesó en S. Felipe de Madrid el 1 de junio de 1601, diez años después de la muerte del beato. Cfr. Archivo Agustiniano 70 (1986) 79. 
que habían dado importantes declaraciones sobre la vida del beato, con el fin de conferirles mayor crédito. Fueron ellos los PP. Diego Ramírez, Juan de Miranda y Diego de Campo ${ }^{67}$.

Del P. Diego Ramírez se escribe que era predicador y conventual de $\mathrm{S}$. Felipe y de 58 años de edad. Hizo declaración favorable sobre los PP. Cristóbal de Fonseca, Diego Guiérrez, Bartolomé de Legarda, Juan Quijano, Luis de los Ríos, Andrés de Urosa, Juan de los Santos, Alonso de Soto, Matías de Ontiveros y Juan de Medina. A algunos de ellos los conocía de cuarenta años a esta parte, a otros menos hasta ocho, pero de todos tenía un alto concepto por sus cualidades religiosas.

Al P. Juan de Miranda se le califica como "maestro en la Santa Teología, consultor y calificador, teólogo del Consejo Supremo de la Inquisición, lector que ha sido de teología más de diez y seis años". Era también conventual en S. Felipe, tenía "más de 50 años" y declaró en abono de los mismos religiosos, a quienes dice haber conocido a algunos más de 20 años, a otros 16 , a otros 8, etc.

Por su parte el P. Diego de Campo ${ }^{68}$ se presenta como "maestro en Santa Teología, consultor y calificador teólogo del Consejo Supremo de la Inquisición, lector de teología que ha sido muchos años y prior que ha sido del insigne convento de San Agustín de Burgos y de San Agustín de Medina del Campo y de San Agustín de Soria", siendo al presente conventual en S. Felipe de Madrid. Este religioso tenía 70 años y ofrece un testimonio semejante sobre los Padres arriba indicados, aunque no dice desde cuanto tiempo los conocía.

Carlos Alonso

67. Proceso, pp. 136-140.

68. T. de HerRera, Historia, p. 349 cita brevemente al P. Diego de Campo, que había profesado en Salamanca en 1575 y era hermano del más conocido P. Felipe de Campo. 